\title{
Application of Thermal Insulation Gunite Material to the High Geo-Temperature Roadway
}

\author{
Junhui Wang $\mathbb{D}^{1}{ }^{1}$ Zhijun Wan $\mathbb{D}^{1},{ }^{1}$ Hongwei Zhang $\mathbb{D}^{2},{ }^{2}$ Dong Wu, ${ }^{1}$ Yuan Zhang, ${ }^{1}$ Yi Wang, ${ }^{3}$ \\ Luchang Xiong, ${ }^{1}$ and Guoli Wang ${ }^{4}$ \\ ${ }^{1}$ Key Laboratory of Deep Coal Resource Mining (CUMT), Ministry of Education of China, School of Mines, \\ China University of Mining and Technology, Xuzhou 221116, Jiangsu, China \\ ${ }^{2}$ School of Energy and Mining Engineering, China University of Mining and Technology, Beijing 100083, China \\ ${ }^{3}$ College of Safety and Emergency Management Engineering, Taiyuan University of Technology, Taiyuan 030024, Shanxi, China \\ ${ }^{4}$ Dananhu No. 1 Coal Mine, CHN ENERGY Investment Group Co., Ltd., Hami 839000, China
}

Correspondence should be addressed to Zhijun Wan; zhjwan@cumt.edu.cn and Hongwei Zhang; hongwei@cumtb.edu.cn

Received 5 March 2020; Accepted 31 July 2020; Published 19 August 2020

Academic Editor: Zhiqiang Yin

Copyright ( 2020 Junhui Wang et al. This is an open access article distributed under the Creative Commons Attribution License, which permits unrestricted use, distribution, and reproduction in any medium, provided the original work is properly cited.

\begin{abstract}
Thermal insulation gunite (TIG) in roadways is an effective method for regional thermal hazard control in mines. The development of mine TIG materials is the foundation of thermal insulation technique. However, some conventional and advanced insulation materials are inapplicable to deep mines which are rather humid with high in situ stress and high geo-temperature. In this study, a kind of fly ash-inorganic mineral TIG material was developed and applied to the modelling of a high geo-temperature roadway. Moreover, the thermal insulation effect of the TIG layer was analyzed, and the temperature field characteristics of the TIG surrounding rock were discussed. Results reveal that (1) the TIG layer has a significant impact on the heat release of the wall and stability of the surrounding rock temperature field; (2) the initial temperature disturbance times, temperature disturbance ranges, and temperature drop rates differ with whether a TIG layer exists or not; (3) after the TIG roadway starts to be ventilated, the thermal flux densities tend to be consistent, which indicates the end of temperature disturbance; besides, the dimensionless temperature shares an exponential relation with the dimensionless radius; and (4) the characteristics of temperature drops vary with the radial positions of the surrounding rock. The research results provide a certain reference for thermal hazard control, temperature prediction, and ventilation network adjustment.
\end{abstract}

\section{Introduction}

Thermal hazards, one of the common problems in modern mines, are an inevitable geological disaster in the process of mine development to the deep [1-3]. The problem of thermal hazards appeared earlier in developed mining countries such as the United States [4], Australia [5], Poland [6], and South Africa [7]. To this day, there have been about 140 high geo-temperature mines in China $[8,9]$. High geotemperature is the main reason for the formation of thermal hazards which are inevitably brought about by deep mining [10-12]. By 2016, there have been 47 coal mines whose depths exceed $1,000 \mathrm{~m}$ in China $[13,14]$, such as the Suncun Coal Mine $\left(1,501 \mathrm{~m}\right.$, geo-temperature $\left.48^{\circ} \mathrm{C}\right)$, Sanhejian Coal
Mine $\left(1,010 \mathrm{~m}\right.$, geo-temperature $\left.46.8^{\circ} \mathrm{C}\right)$, and Zhangji Coal Mine $\left(1,260 \mathrm{~m}\right.$, geo-temperature $\left.51.5^{\circ} \mathrm{C}\right)$ [8], and over 150 coal mines whose depths exceed $1,000 \mathrm{~m}$ abroad, such as the Pniowek Coal Mine $\left(1,000 \mathrm{~m}\right.$, geo-temperature $\left.45^{\circ} \mathrm{C}\right)$ in Poland [6]. In addition, some coal mines which are 600-1,000 m deep have high geo-temperatures as a result of local heat accumulation, such as the Pingdingshan No. 8 Coal Mine $\left(660 \mathrm{~m}\right.$, geo-temperature $\left.43^{\circ} \mathrm{C}\right)$ [1]. Domestic and foreign researches on cooling of high geo-temperature mines are mainly focused on mechanical cooling technique $[7,15]$, including central air conditioning cooling, ice cooling, air cooling [16], electric-thermal-glycol cooling, and deep well HEMS cooling [17]. However, the high cost, large cooling capacity losses, and large energy consumption of mechanical 
cooling bring considerable burden to enterprises. The thermal insulation and cooling of a roadway is to shoot the mine thermal insulation materials on the roadway surface with high surrounding rock temperature, so as to reduce heat transfer from high-temperature rock to air flow. This method, in combination with the adjustment of ventilation parameters, can achieve a good cooling effect with a relatively low cost [9]. Therefore, the research on the thermal insulation and cooling of roadways is of great significance for the control of regional thermal hazards and the efficient exploitation of resources in mines.

The development of mine thermal insulation gunite material (TIG material) is the basis for the application of thermal insulation and cooling to roadways. Mine TIG materials are required not only to feature light weight, thermal insulation, and flame retardance but also to possess high mechanical properties. These requirements make certain materials that are commonly used in construction and chemical fields unsuitable for use in mine roadways, such as form materials (EPS, XPS, phenolic foam, and polyurethane), fibrous materials (stone wool and glass wool), and advanced materials (vacuum insulation panels, gas filed panels, and aerogel) [18, 19]. Foreign scholars rarely conducted researches on TIG materials, and Chinese scholars mainly focused on inorganic mineral materials such as expanded perlite, vitrified microsphere, and vermiculite. Fly ash, a solid waste produced by the rapid oxidation of pulverized coal during thermal power generation [20], is enormously produced in China (686 million $t$, 2017). It features multiple holes, low density and low thermal conductivity, and is pretty economical [21, 22]. Therefore, fly ash-inorganic mineral insulation materials are advantageous in mining. The previous literature pays more attention to the development of materials and takes thermal conductivity as the evaluation standard, but the developed materials are seldom applied in the field. Li et al. [23] developed a kind of TIG material by taking vitrified microsphere, cement, sand, and aluminum powder as the raw materials. Then, through an industrial application of the material, they found that the heat release from the shotcrete roadway was reduced by $64 \%$. By studying the composition and ratio of raw materials, Zhang [24], Yang [25], and Zhu [26] obtained thermal insulation materials with a better performance. Liu [27] and Wang [28] simulated the temperature distribution of a TIG roadway with the aid of Fluent software. Zhou [29] discussed the influence of thermophysical parameters of the TIG layer on its thermal insulation effect. It can be concluded that scholars mostly evaluated the thermal insulation effect of TIG materials in high geo-temperature roadways by means of numerical simulation. Nevertheless, since the unstable heat transfer coefficients of the roadways are difficult to determine, the simulation results differ notably from the actual situation.

Therefore, despite some previous achievements made in the development of TIG materials, there is still a lack of researches on the thermal insulation effect of mine TIG materials and the influence of TIG layers on the temperature field of surrounding rock. Physical simulation experiments provide us with solutions. Wang [30], Zhang [31], Zhu [32], and Wang [33] analyzed the temperature and humidity fields of air flow and surrounding rock with the aid of similar simulation devices, but their conclusions were all targeted at non-TIG roadways. On the basis of previous studies, the influence of the TIG layer on the geo-temperature field was investigated by using a similarity simulation device (Figure 1) in this paper. The investigation can serve to evaluate the thermal insulation effect of TIG materials. Besides, it is meaningful for the prediction of airflow and rock temperature and the adjustment and optimization of the ventilation network. Ultimately, it conduces to the control of thermal hazards in mines.

This paper is focused on the application of a kind of fly ash-inorganic mineral thermal insulation material to the high geo-temperature roadway. The specific objectives of this study are (a) to develop a kind of mine TIG material which achieves both roadway support and thermal insulation; (b) to compare and verify the thermal insulation effect of the TIG layer; and (c) to analyze the temperature field characteristics of the TIG roadway.

\section{Materials and Methods}

2.1. Experimental Apparatus. As displayed in Figure 2, the physical similarity simulation experimental apparatus for a high geo-temperature TIG roadway mainly consists of a surrounding rock heating system, a modelling roadway, a constant temperature and humidity ventilation system, and a data acquisition system. The apparatus has a geometric similarity constant $C_{l}=20$, a time similarity constant $C_{\tau}=400$, and a wind speed similarity constant $C_{v}=0.05$. Detailed design of the experimental apparatus can be found in the literature [9].

The surrounding rock heating system, which contains a closed loop constituted by a rectifier, electric heating electrodes, an alloy heating net, copper plates, and other components, works by outputting low voltage and high current through the thyristor rectifier. With the aid of the alloy heating net, the system can heat the cylinder through stepless adjustment of output current in the range of 0-1000 A. The constant temperature and humidity ventilation system can provide air flow conditions in the temperature range of $5^{\circ} \mathrm{C}-45^{\circ} \mathrm{C}$, the humidity range of $20 \%-90 \%$, and a maximum air volume of $5000 \mathrm{~m}^{3} / \mathrm{h}$. The modelling roadway is composed of six cylinders, each of which has a length of $1 \mathrm{~m}$, an inner diameter of $0.8 \mathrm{~m}$, and an outer diameter of $1 \mathrm{~m}$. In the $0.1 \mathrm{~m}$ space between the inner wall and the outer wall, mica paper, alloy heating net, mica paper, and thermal insulation asbestos are arranged, respectively. Temperature sensors are arranged at the positions of $0.9 \mathrm{R}, 1 \mathrm{R}, 2 \mathrm{R}, 3 \mathrm{R}$, and $4 \mathrm{R}$.

2.2. Materials of the Surrounding Rock and TIG Layer. Surrounding rock materials (the range of $1 \mathrm{R}-4 \mathrm{R}$ ) and TIG layer materials (the range of $0.9 \mathrm{R}-1 \mathrm{R}$ ) were poured or built into the cylinders, as shown in Figure 2.

The surrounding rock material was made of high-purity quartz sand and river sand as the fine aggregates and iron 


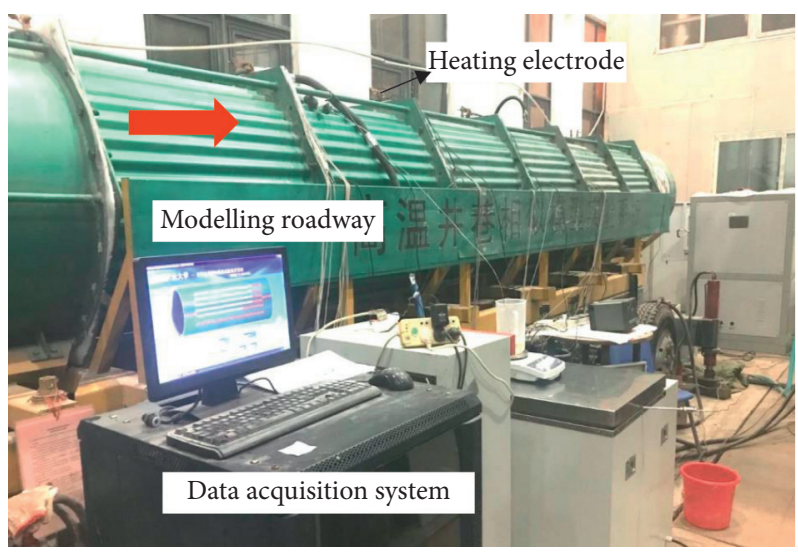

FIgURE 1: The experimental apparatus.

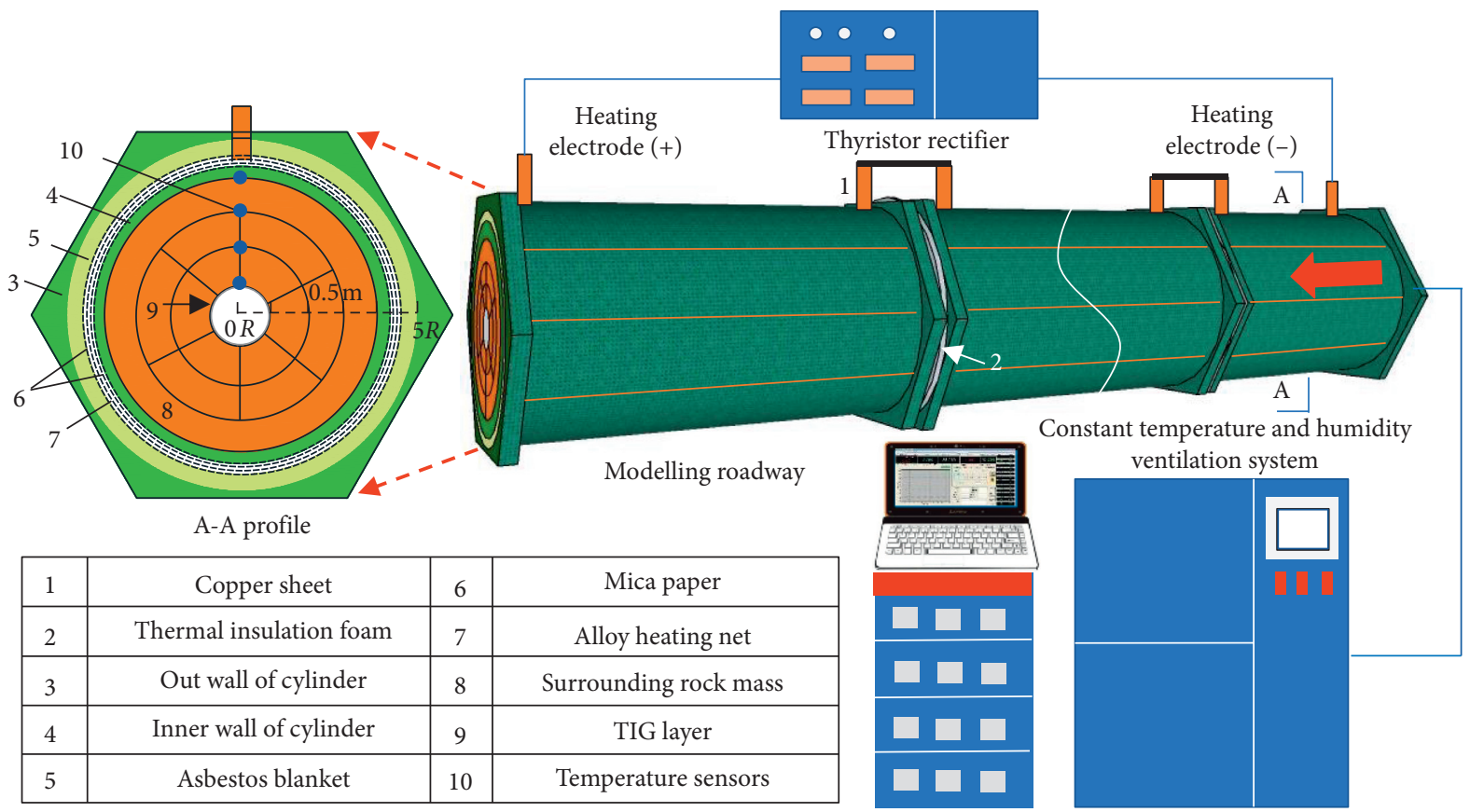

FIgURE 2: Schematic diagram of the experimental apparatus.

powder (to improve thermal conductivity) as the additive. The ratio and thermophysical properties are given in Table 1 $[9,31]$. For the material, the thermal conductivity $\lambda_{2}$ was $1.2 \mathrm{~W} /(\mathrm{m} \cdot \mathrm{K})$ and the thermal diffusivity $\alpha_{2}$ was $0.8 \times 10-6 \mathrm{~m}^{2} / \mathrm{s}$. Three layers of surrounding rock material were arranged within the range of $1 \mathrm{R}-4 \mathrm{R}$ in the cylinders in Figure 1, of which the material within $1 \mathrm{R}-3 \mathrm{R}$ was built and cured by the mould while that within $3 \mathrm{R}-4 \mathrm{R}$ was directly poured in the cylinders.

The TIG material was composed of 425 ordinary Portland cement (28d uniaxial compressive strength $\geq 36 \mathrm{MPa}$ ), river sand (particle size $<1 \mathrm{~mm}$ ), and fly ash (particle size $<0.5 \mathrm{~mm}$ ). Besides, it was added with a certain amount of vitrified microsphere (particle size $=0.5-1 \mathrm{~mm}$; thermal conductivity $<0.043 \mathrm{~W} /(\mathrm{m} \cdot \mathrm{K}))$ for enhancing its thermal insulation performance. The TIG layer was arranged within the range of $0.9 \mathrm{R}-1 \mathrm{R}$ in the cylinders, as in Figure 2.

\subsection{Experimental Scheme}

2.3.1. Development of the TIG Material. The TIG material should meet the requirements of thermal insulation, light weight, and excellent load-bearing capacity. To explore the material performance under different ratios, a three factor and three-level orthogonal experiment was designed. As listed in Table 2, the three factors are fly ash, vitrified microsphere, and river sand, and the three levels are three ratios corresponding to each raw material. Since cement can improve the mechanical properties of the material significantly, it is not researched on any more here.

The nine groups of experimental samples with varying ratios were numbered $1-9$, representing level combinations $\mathrm{A} 1 \mathrm{~B} 1 \mathrm{C} 1, \mathrm{~A} 1 \mathrm{~B} 2 \mathrm{C} 2, \mathrm{~A} 1 \mathrm{~B} 3 \mathrm{C} 3, \mathrm{~A} 2 \mathrm{~B} 1 \mathrm{C} 3, \mathrm{~A} 2 \mathrm{~B} 2 \mathrm{C} 1, \mathrm{~A} 2 \mathrm{~B} 3 \mathrm{C} 2$, $\mathrm{A} 3 \mathrm{~B} 1 \mathrm{C} 2, \mathrm{~A} 3 \mathrm{~B} 2 \mathrm{C} 3$, and $\mathrm{A} 3 \mathrm{~B} 3 \mathrm{C} 1$, respectively. In each group, three $70.7 \mathrm{~mm} \times 70.7 \mathrm{~mm} \times 70.7 \mathrm{~mm}$ cubic samples and one $400 \mathrm{~mm} \times 400 \mathrm{~mm} \times 30 \mathrm{~mm}$ plate sample were prepared. 
TABLE 1: Ratio and properties of similar material for surrounding rock [9].

\begin{tabular}{cccccc}
\hline Cement & River sand & Quartz sand & Thermal conductive powder & Water-cement ratio & $\begin{array}{c}\text { Thermophysical property } \\
\lambda_{2}(\mathrm{~W} /(\mathrm{m} \cdot \mathrm{K}))\end{array}$ \\
$\alpha_{2}\left(\mathrm{~m}^{2} / \mathrm{s}\right)$
\end{tabular}

TABLE 2: Scheme of orthogonal experiment on the material ratio.

\section{Factor}

\begin{tabular}{cccc} 
Level & $\begin{array}{c}\text { Fly ash A } \\
(\%)\end{array}$ & $\begin{array}{c}\text { Vitrified microsphere B } \\
(\%)\end{array}$ & $\begin{array}{c}\text { River sand C } \\
(\%)\end{array}$ \\
\hline 1 & 40 & 10 & 60 \\
2 & 50 & 20 & 80 \\
3 & 60 & 30 & 100 \\
\hline
\end{tabular}

Note. The percentages are obtained from the ratios of masses of corresponding materials to the total mass of cement and fly ash.

During sample preparation, the materials at the corresponding ratio were added with a certain amount of water and stirred evenly. Next, the evenly stirred mixture was injected into three-groove moulds, vibrated, and compacted. After $24 \mathrm{~h}$, the samples were demoulded and placed in the curing room to be cured standardly (temperature $20 \pm 2^{\circ} \mathrm{C}$; humidity over 95\%) for $28 \mathrm{~d}$.

Three basic physical and mechanical parameters, namely, apparent density, uniaxial compressive strength (UCS), and thermal conductivity, of the nine groups of samples were measured. The apparent density was obtained by measuring the mass and volume; the compressive strength was measured by using a compression testing machine (MTS/SANS CMT5105); and the thermal conductivity was measured by the method of a plate heat flux meter (DRPL-400 thermal conductivity tester produced in Xiangtan, China).

\subsubsection{Application of the TIG Material to the High Geo-} Temperature Roadway. To investigate the application effect of the mine TIG material to the high geo-temperature roadway, two groups of experiments were performed with the aid of the physical similarity simulation experimental apparatus. The first group aims to investigate the temperature field of surrounding rock of a non-TIG roadway, namely, the roadway without a TIG layer (see Scheme 1 in Table 3 for the working conditions), while the second group aims to explore that of a TIG roadway, namely, the roadway with a TIG layer (see Schemes 1-4 in Table 3 for the working conditions).

2.4. Method for Data Analysis. The experimental data were subjected to dimensionless processing. After the processing, the dimensionless temperature, radius, and time expressions become $T=\left(t-t_{f}\right) /\left(t_{0}-t_{f}\right), R=r / r_{1}$, and $F_{0}=\alpha_{2} * r /\left(r 1_{2}\right)$, respectively. In the expressions, $T, R$, and $F_{0}$ represent the dimensionless temperature, radius, and time, respectively; $t_{0}$ is the temperature of virgin rock, ${ }^{\circ} \mathrm{C}$; $t_{f}$ is the temperature of inlet air, ${ }^{\circ} \mathrm{C}$; $t$ is the temperature of the measuring point, ${ }^{\circ} \mathrm{C} ; r$ is the distance from a certain point to the center of roadway, $m ; r_{1}$ is the inner radius of roadway, $0.1 \mathrm{~m} ; \alpha_{2}$ is the thermal diffusivity of surrounding rock, $\mathrm{m}^{2} / \mathrm{s}$; and $\tau$ is the ventilation time, $s$. Because the relation between dimensionless quantities is universally applicable, the experimental data need not be calculated into the real model according to the similar constant relations.

\section{Results and Discussion}

3.1. The Optimum Ratio of the TIG Material. Figure 3 illustrates the apparent density, thermal conductivity, and UCS data of nine groups of compounded samples. As displayed in Figure 3, the physical and mechanical properties of samples differ notably but vary in basically consistent patterns overall. For the samples, the apparent density, thermal conductivity, and UCS lie in the ranges of $1200-1630 \mathrm{~kg} / \mathrm{m}^{3}$, $0.119-0.181 \mathrm{~W} /(\mathrm{m} \cdot \mathrm{K})$, and $4.8-11.7 \mathrm{MPa}$, respectively.

Table 4 gives the range analysis results of apparent density, thermal conductivity, and UCS of the nine groups of compounded samples (the data are derived from Figure 3). It can be known from Table 4 that the three factors are vitrified microsphere (B), fly ash (A), and river sand (C) in descending order of their degrees of influence on the apparent density. The optimal level combination for apparent density is $\mathrm{A} 2 \mathrm{~B} 3 \mathrm{C} 1$, i.e., fly ash (50\%), vitrified microsphere (30\%), and river sand (60\%). The three factors are vitrified microsphere (B), river sand (C), and fly ash (A) in descending order of their degrees of influence on the thermal conductivity. The optimal level combination for thermal conductivity is also $\mathrm{A} 2 \mathrm{~B} 3 \mathrm{C} 1$. The three factors are river sand (C), fly ash (A), and vitrified microsphere (B) in descending order of their degrees of influence on the UCS. The optimal level combination of $28 \mathrm{~d}$ UCS is A1B1C2, i.e., fly ash (40\%), vitrified microsphere (10\%), and river sand (80\%).

From the analysis of data in Figure 3 and Table 4, the apparent density, thermal conductivity, and UCS of the samples change synchronously, except some data points that vary due to experimental errors. That is, the sample with a small apparent density generally possesses a small thermal conductivity and a low UCS. The range analysis demonstrates that vitrified microsphere remarkably reduces the weight of the material and improves the thermal insulation performance, but it notably causes damage to the loadbearing capacity of the material. Hence, fly ash and cement become important factors balancing the relationship among weight reduction, thermal insulation, and load-bearing capacity.

To determine the optimal ratio of the material, the method of efficacy coefficient was adopted. It is assumed that $n$ indexes (three indexes in this experiment, namely, apparent density, thermal conductivity, and UCS) are examined and that the efficiency coefficient of each index is di 
TABle 3: Experimental scheme.

\begin{tabular}{lcccc}
\hline Parameter & Scheme 1 & Scheme 2 & Scheme 3 & Scheme 4 \\
\hline Virgin rock temperature $t_{0}\left({ }^{\circ} \mathrm{C}\right)$ & 37 & 37 & 37 & 39 \\
Inlet air temperature $t_{f}\left({ }^{\circ} \mathrm{C}\right)$ & 20 & 20 & 10 & 20 \\
Average wind speed $v(\mathrm{~m} / \mathrm{s})$ & 5 & 7 & 5 & 5 \\
\hline
\end{tabular}

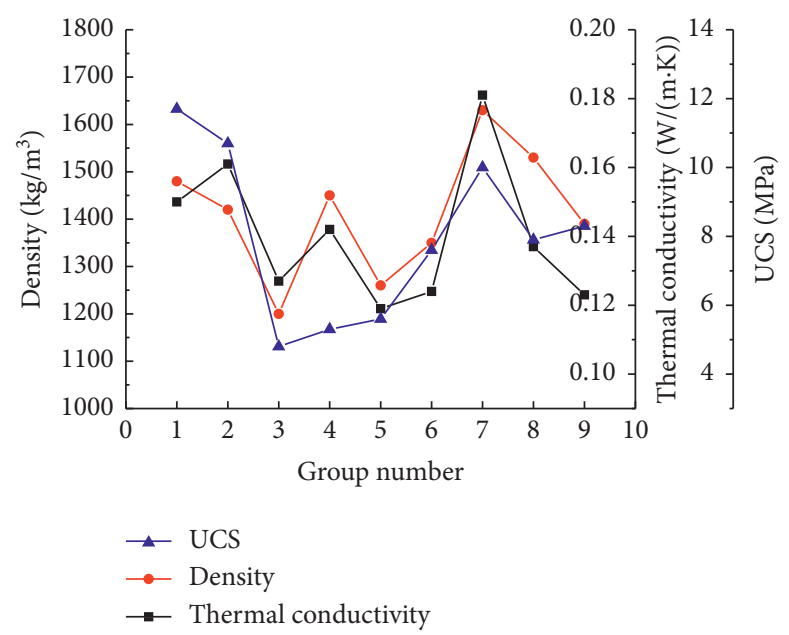

FIGURE 3: Physical and mechanical properties data of compounded samples.

TABLE 4: Range analysis results.

\begin{tabular}{|c|c|c|c|c|c|c|c|c|c|}
\hline \multirow{2}{*}{ Parameters } & \multicolumn{3}{|c|}{ Apparent density $\left(\mathrm{kg} / \mathrm{m}^{3}\right)$} & \multicolumn{3}{|c|}{ Thermal conductivity $(\mathrm{W} /(\mathrm{m} \cdot \mathrm{K}))$} & \multicolumn{3}{|c|}{ UCS (MPa) } \\
\hline & $\mathrm{A}$ & $\mathrm{B}$ & $\mathrm{C}$ & A & $\mathrm{B}$ & $\mathrm{C}$ & A & $\mathrm{B}$ & $\mathrm{C}$ \\
\hline$\overline{K_{1}}$ & 1367 & 1520 & 1377 & 0.146 & 0.158 & 0.131 & 9.1 & 9.1 & 8.5 \\
\hline$K_{2}$ & 1353 & 1403 & 1467 & 0.128 & 0.139 & 0.155 & 6.2 & 8.1 & 9.4 \\
\hline$K_{3}$ & 1517 & 1313 & 1393 & 0.147 & 0.125 & 0.135 & 8.7 & 6.9 & 6 \\
\hline Range $\mathrm{R}$ & 164 & 207 & 90 & 0.019 & 0.033 & 0.024 & 2.9 & 2.2 & 3.4 \\
\hline Influence degree & & $\mathrm{B}>\mathrm{A}>\mathrm{C}$ & & & $\mathrm{B}>\mathrm{C}>\mathrm{A}$ & & & $\mathrm{C}>\mathrm{A}>\mathrm{B}$ & \\
\hline Optimal level & $\mathrm{A} 2$ & B3 & $\mathrm{C} 1$ & A2 & B3 & $\mathrm{C} 1$ & A1 & B1 & $\mathrm{C} 2$ \\
\hline Optimal combination & & $\mathrm{A} 2 \mathrm{~B} 3 \mathrm{C} 1$ & & & $\mathrm{~A} 2 \mathrm{~B} 3 \mathrm{C} 1$ & & & $\mathrm{~A} 1 \mathrm{~B} 1 \mathrm{C} 2$ & \\
\hline
\end{tabular}

$(0 \leq d i \leq 1)$. If the $i$ th examined index is the optimal index, its efficiency coefficient is 1 , i.e., $d i=1$. Efficiency coefficients of the other indexes are ratios of these indexes to the optimal index. Then, the total efficiency coefficient is $d=\sqrt[n]{d_{1} \cdot d_{2} \ldots d_{n}}$. The greater the total efficacy coefficient is, the better the ratio is. The results are listed in Table 5 The data are derived from Figure 3).

As can be observed from Table 5, $d=0.86$ (fly ash $40 \%$, vitrified microsphere $10 \%$, river sand $60 \%$ ) in Group 1 is the largest efficiency coefficient. In other words, the ratio of Group 1 is the optimal ratio. From the perspective of material properties, the thermal insulation material with this ratio can balance roadway support and thermal insulation. With a density of $1480 \mathrm{~kg} / \mathrm{m}^{3}$, it meets the requirement for lightweight concrete $1950 \mathrm{~kg} / \mathrm{m}^{3}$; its thermal conductivity $0.15 \mathrm{~W} /(\mathrm{m} \cdot \mathrm{K})$ meets the requirement for thermal insulation material $0.23 \mathrm{~W} /(\mathrm{m} \cdot \mathrm{K})$; and it boasts a UCS of $11.7 \mathrm{MPa}$ which exceeds the strength $(10 \mathrm{MPa})$ of $\mathrm{C} 10$ concrete.
3.2. The Heat Reduction of the TIG Layer. The experimental data of the TIG roadway and non-TIG roadway were compared under the conditions of the virgin rock temperature $t_{0}=37^{\circ} \mathrm{C}$, inlet temperature $t_{f}=20^{\circ} \mathrm{C}$, and average wind speed $v=5 \mathrm{~m} / \mathrm{s}$. Figures 4 and 5 exhibit the temperature distribution characteristics of radial points ( $1 \mathrm{R}-4 \mathrm{R})$ in the surrounding rock and their dynamic variations with time in the two experimental cases.

When dimensionless temperature $T$ in the surrounding rock falls to 0.99 , it is considered that thermal disturbance occurs in the surrounding rock. In the non-TIG roadway, thermal disturbance occurs at $1 \mathrm{R}$ and $2 \mathrm{R}$ of the surrounding rock when the dimensionless time $F_{0}=0.1$; it occurs at $3 \mathrm{R}$ when $F_{0}=0.2$ and at $4 \mathrm{R}$ when $F_{0}=0.4$. Radial points $(1 \mathrm{R}-4 \mathrm{R})$ in the surrounding rock undergo thermal disturbance earlier for the non-TIG roadway than the TIG one.

For the non-TIG roadway wall, the initial and end dimensionless temperatures $T$ are $0.73\left(F_{0}=0.1\right)$ and 0.51 $\left(F_{0}=0.8\right)$, respectively, while for the TIG roadway wall, the 
TABLE 5: Analysis of the efficacy coefficient model.

\begin{tabular}{lcccc}
\hline Group no. & $\begin{array}{c}\text { Efficiency coefficient } \\
\text { Apparent density }\left(\mathrm{kg} / \mathrm{m}^{3}\right)\end{array}$ & Thermal conductivity $(\mathrm{W} /(\mathrm{m} \cdot \mathrm{K}))$ & $\mathrm{UCS}(\mathrm{MPa})$ & Total efficiency coefficient $d=\sqrt[3]{d_{1} \cdot d_{2} \cdot d_{3}}$ \\
\hline 1 & 0.81 & 0.79 & 1.00 & 0.86 \\
2 & 0.85 & 0.74 & 0.91 & 0.83 \\
3 & 1.00 & 0.94 & 0.41 & 0.73 \\
4 & 0.83 & 0.84 & 0.45 & 0.68 \\
5 & 0.95 & 1.00 & 0.48 & 0.77 \\
6 & 0.89 & 0.96 & 0.65 & 0.82 \\
7 & 0.74 & 0.66 & 0.85 & 0.75 \\
9 & 0.78 & 0.87 & 0.68 & 0.77 \\
9
\end{tabular}

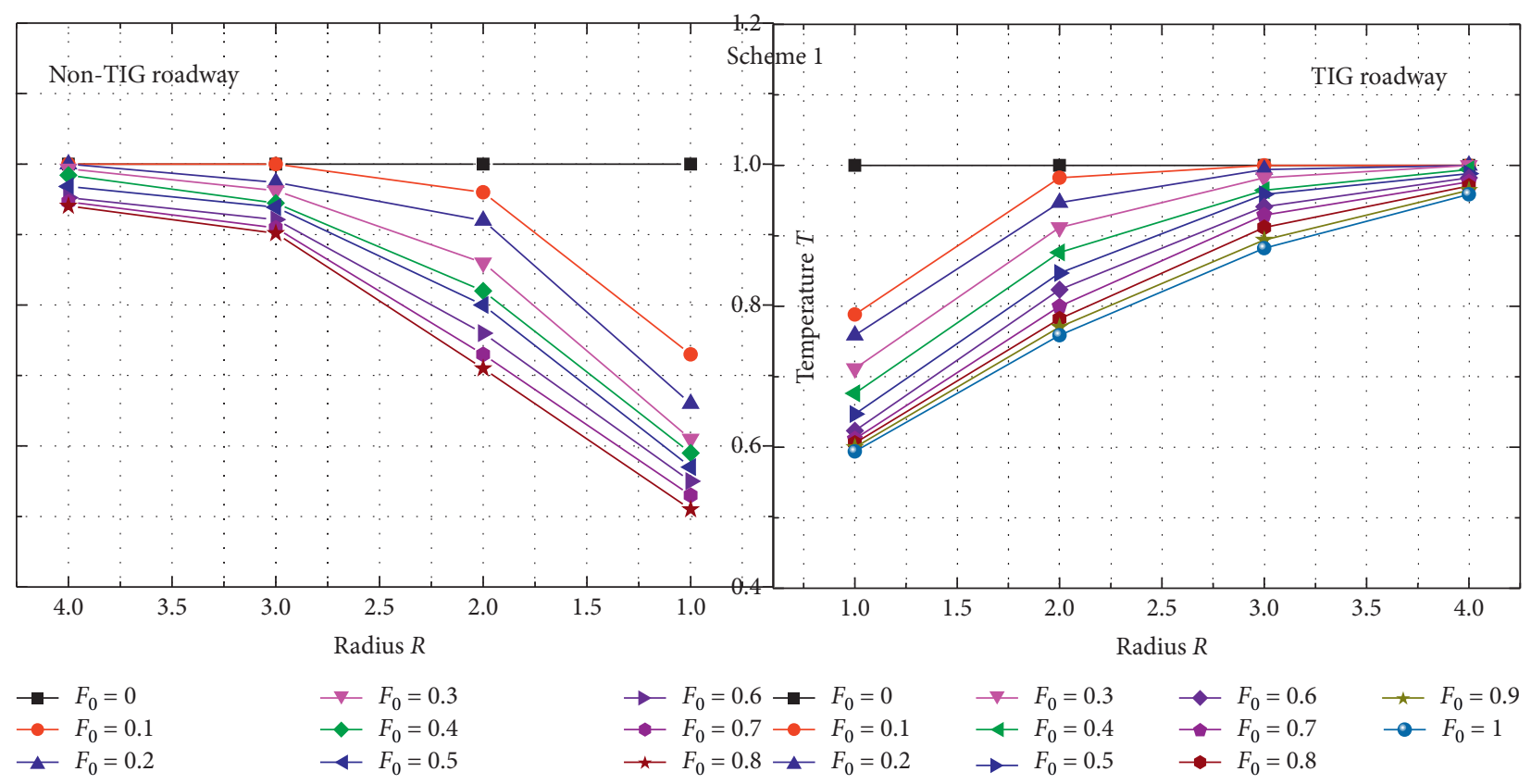

FIGURE 4: $T-R$ curves of the TIG roadway and non-TIG roadway.

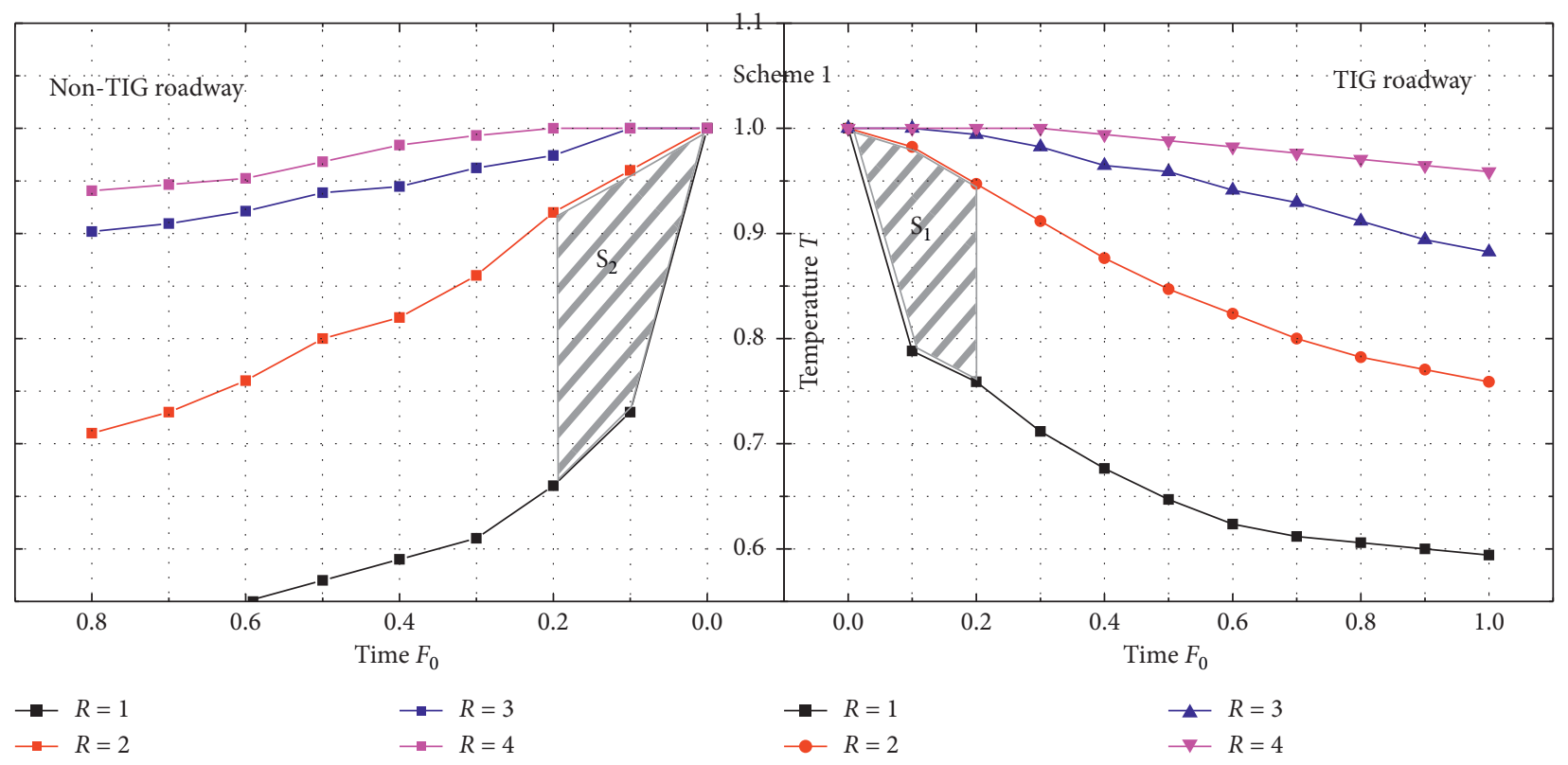

Figure 5: $T-F_{0}$ curves of the TIG roadway and non-TIG roadway. 
initial and end dimensionless temperatures $T$ are 0.79 $\left(F_{0}=0.1\right)$ and $0.6\left(F_{0}=0.8\right)$, respectively. The temperature drop range and rate of the surrounding rock $(2 \mathrm{R}-4 \mathrm{R})$ are both greater for the non-TIG roadway than for the TIG roadway. Obviously, the TIG layer prevents heat in the deep surrounding rock from dissipating to the airflow in the roadway and plays a significant role in cooling the roadway.

To interpret the thermal insulation effect of the TIG layer, it is necessary to calculate the amount of heat reduction. In engineering, the amount of heat release (or heat absorption) from surrounding rock can be calculated in accordance with the following formula:

$$
Q=K_{\tau} U L\left(t_{0}-t_{f}\right)
$$

where $Q$ is the amount of heat released from surrounding rock, $\mathrm{W} ; K_{\tau}$ is the coefficient of unstable heat transfer between surrounding rock and airflow, $\mathrm{W} /\left(\mathrm{m}^{2} \cdot \mathrm{K}\right) ; U$ is the perimeter of the roadway interface, $\mathrm{m}$; and $L$ is the length of the roadway, $m$.

The value of the coefficient of unstable heat transfer $K_{\tau}=f\left(F_{0}, B_{i}\right)$ is difficult to obtain by this experimental system. The analysis indicates that it is through the roadway wall that heat dissipates from the surrounding rock in the high geo-temperature roadway to the airflow. The heat loss $Q$ equals the integral of heat flow rate $q$ in the unit area $A$ to the time $\tau$, i.e.,

$$
Q=\int_{0}^{\tau} q \mathrm{~d} \tau=-\int_{0}^{\tau} \lambda_{2} \frac{\partial t}{\partial r} \mathrm{~d} \tau
$$

In this experiment, the homogeneous surrounding rock material has the same thermal conductivity $\lambda_{2}$. The slope of curve in Figure 4 numerically equals the temperature gradient $\partial t / \partial r$ of surrounding rock (sharing a linear conversion relationship with $\partial T / \partial R)$. The shadow area in Figure 5 physically means the integral term of the temperature gradient between $1 \mathrm{R}$ and $2 \mathrm{R}$ of surrounding rock (approximately representing the wall) over a period of time. The ratio $\left(S_{2}-S_{1}\right) / S_{2}$ represents the heat reduction per unit wall in a period of time after the high geo-temperature roadway is equipped with a TIG layer. As shown in Table 6, under the experimental conditions, the heat reduction of the roadway wall is $64.2 \%$ in the initial stage of ventilation, whereas it is greatly reduced in the later stage, namely, after $F_{0}>0.3 \sim 0.4$. Thus, the TIG layer should be constructed at the early stage of ventilation.

3.3. The Temperature Field Characteristics of the TIG Roadway. In the similarity experiment of the second group of the TIG roadway, the experimental results reveal that, after the excavation and ventilation of the TIG roadway, the temperature distributions of radial points in the surrounding rock in Schemes 1-4 develop in similar trends and so do their dynamic variations with time in Schemes $1-4$, as illustrated in Figures 6-9. In Figure 6(a), Zone I is the TIG layer zone $(0.9 \mathrm{R}-1 \mathrm{R})$ and Zone II is the surrounding rock zone (1 R-4 R). Here, only the experimental data under the working conditions of Scheme 1 are analyzed.
TABLE 6: Calculation of heat reduction of the roadway wall at different periods.

\begin{tabular}{lccc}
\hline$F_{0}$ & $S_{1}$ & $S_{2}$ & $\begin{array}{c}\text { Heat reduction of the } \\
\text { roadway wall }(\%)\end{array}$ \\
\hline $0-0.1$ & 0.0077 & 0.0215 & 64.2 \\
$0-0.2$ & 0.0222 & 0.0493 & 55.0 \\
$0-0.3$ & 0.0505 & 0.0645 & 21.7 \\
$0-0.4$ & 0.0718 & 0.0890 & 19.3 \\
$0-0.5$ & 0.0914 & 0.1116 & 18.1 \\
$0-0.6$ & 0.1115 & 0.1342 & 16.9 \\
$0-0.7$ & 0.1311 & 0.1542 & 15.0 \\
$0-0.8$ & 0.1492 & 0.1743 & 14.4 \\
\hline
\end{tabular}

3.3.1. Relationship between Dimensionless Temperature $T$ and Dimensionless Radius $R$. As can be observed from Figure 6(a), an obvious exponential function relationship exists between $T$ and $R$ in the surrounding rock zone (Zone II), and the expression is $T=P_{1} \exp \left(P_{2} R\right)+P_{3}$. That is, the temperature of surrounding rock rises gradually with the increase in depth and approximates the temperature of the virgin rock. Partial fitting parameters are displayed in $\mathrm{Ta}-$ ble 7 . The analysis shows that $P_{1}$ and $P_{2}$ are both the functions of $F_{0}$ and $B_{i}$ (Biot number) under the condition of constant airflow state [31].

It can also be seen from Figure 6(a) that (1) the temperature gradient between the TIG layer and the surrounding rock experiences an obvious abrupt change due to the great difference in thermal conductivity of materials; (2) assuming that thermophysical properties inside the surrounding rock are constant, the thermal flux density $(T / R)$ of the surrounding rock near the roadway wall is larger in the early stage of ventilation; the various thermal flux densities $(T / R)$ inside the surrounding rock tend to be consistent as the ventilation time $F_{0}$ increases from 0 to 1 . This indicates that the temperature field of the surrounding rock regains a balance, which marks the end of temperature disturbance.

3.3.2. Thermal Disturbance of the TIG Roadway. From Figure 6, the temperature of the surrounding rock of the TIG roadway is slowly disturbed in the beginning, and the range of disturbance increases gradually with dimensionless time $F_{0}$.

According to the data, when $F_{0}=0.1$, the dimensionless temperatures $T$ of $0.9 \mathrm{R}, 1 \mathrm{R}$, and $2 \mathrm{R}$ are disturbed immediately. Among them, the temperature of the TIG layer wall $(0.9 \mathrm{R})$ drops to $30.6 \%$ of the initial dimensionless temperature; that of roadway wall (1R) declines to $78.8 \%$ of the initial dimensionless temperature; and that of internal surrounding rock $(2 \mathrm{R})$ begins to be slightly disturbed. The dimensionless temperatures of $3 \mathrm{R}$ and $4 \mathrm{R}$ in the surrounding rock do not begin to be disturbed until $F_{0}=0.3$ and $F_{0}=0.5$, respectively.

\subsubsection{Characteristics of Temperature Drop at Different Radial} Positions of the TIG Roadway. The temperatures at $0.9 \mathrm{R}$ and $1 \mathrm{R}$ on both sides of the TIG layer drop suddenly at the beginning of ventilation, but the degrees of drops differ, leading to the formation of a relatively large temperature 


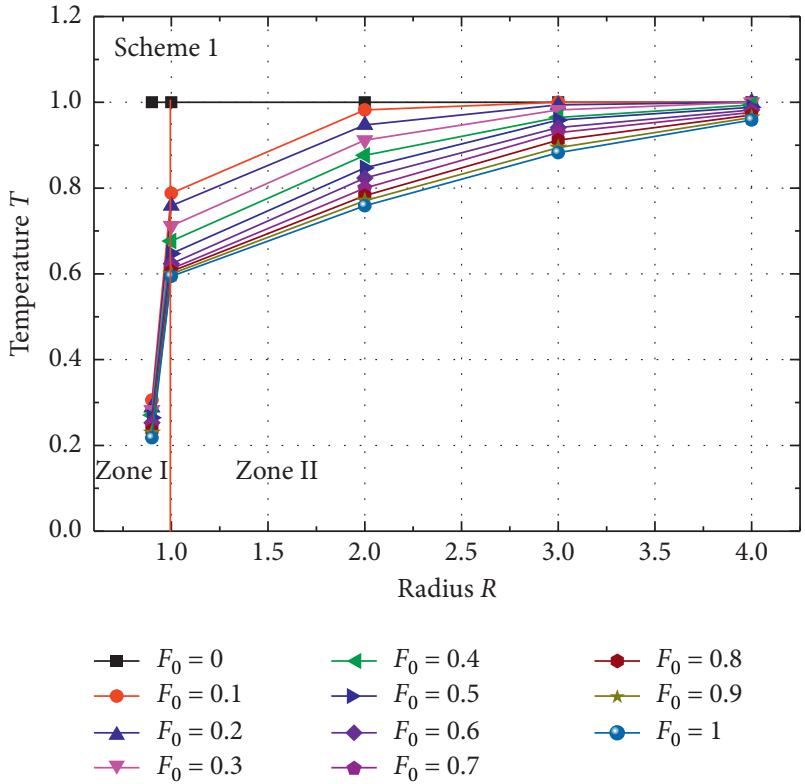

(a)

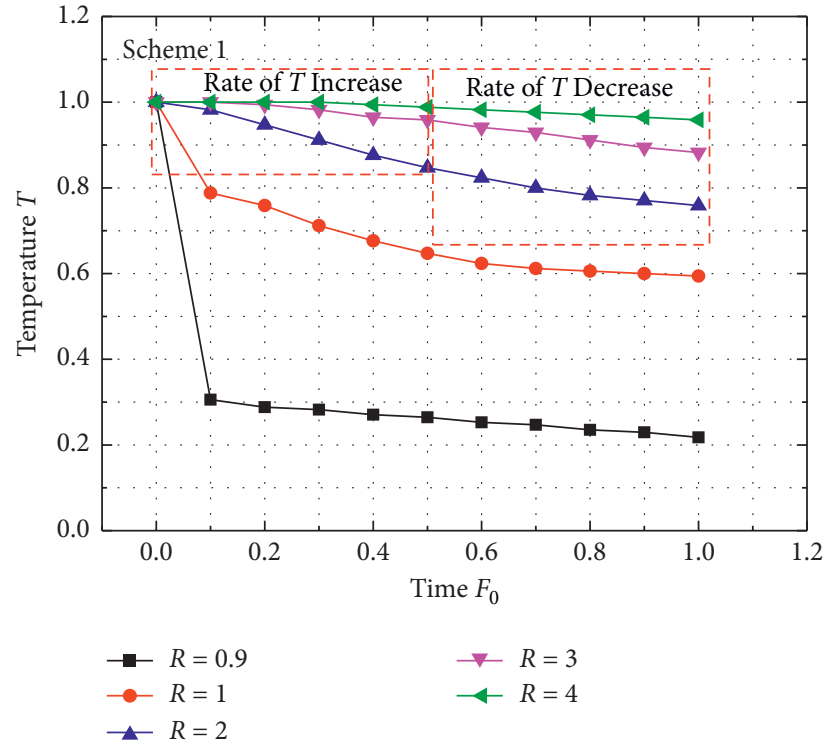

(b)

Figure 6: $T-R$ curve and $T-F_{0}$ curve under the working conditions of Scheme 1. (a) $T-R$ curve. (b) $T-F_{0}$ curve.

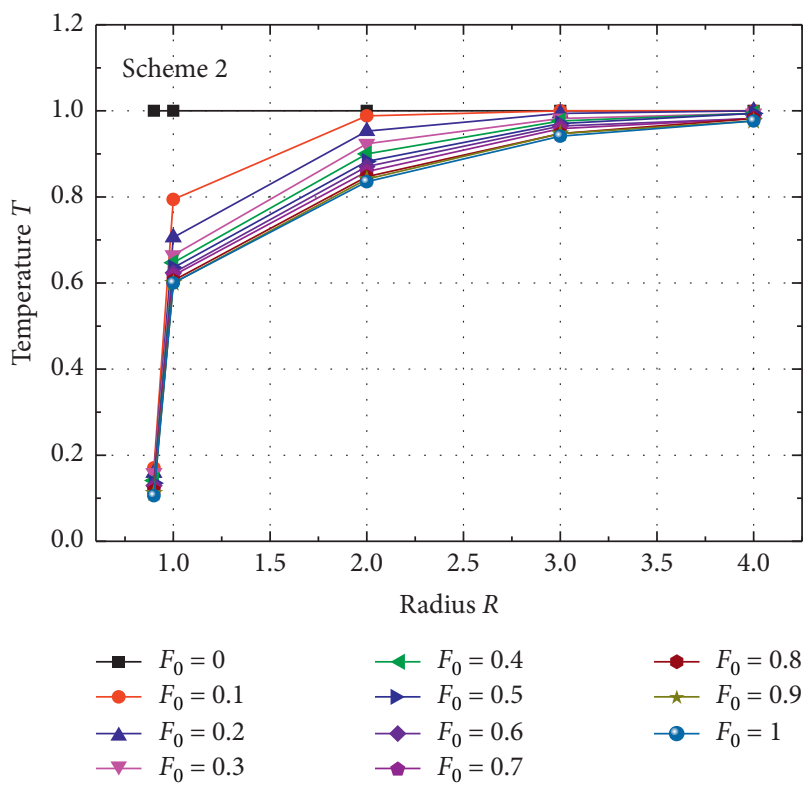

(a)

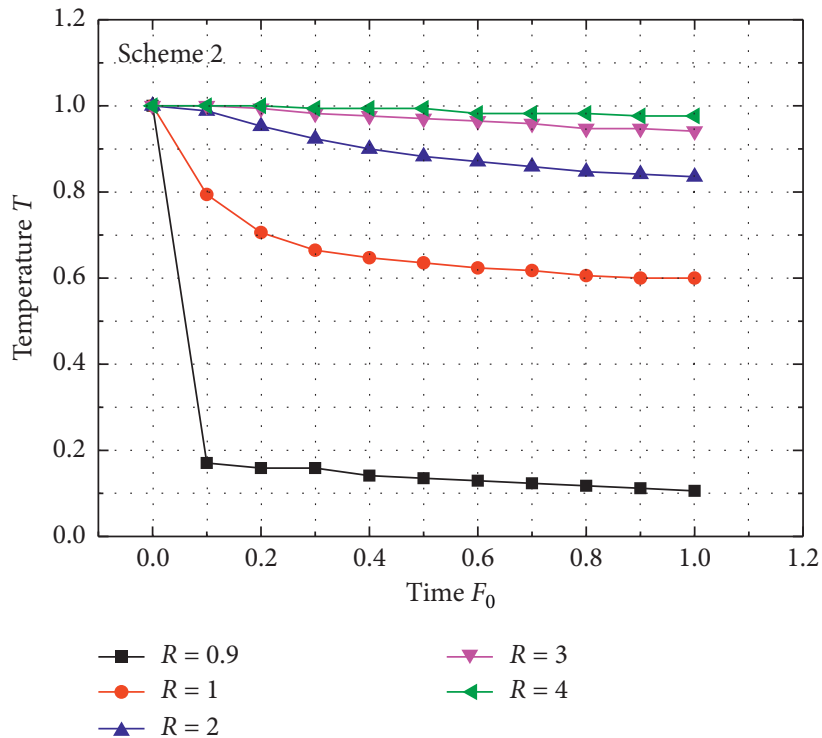

(b)

Figure 7: $T-R$ curve and $T-F_{0}$ curve under the working conditions of Scheme 2. (a) $T-R$ curve. (b) $T-F_{0}$ curve.

difference. The temperature outside the TIG layer $(0.9 \mathrm{R})$ drops in an equal slope; the temperature inside the TIG layer $(1 \mathrm{R})$ declines at a gradually reducing rate; and the temperature inside the surrounding rock $(2 \mathrm{R})$ falls at an increasing rate first and at a decreasing rate later.

(1) TIG Layer Zone (Zone I). The temperature on the TIG layer wall falls sharply at the beginning of ventilation. As presented in Figure 10, after $F_{0}=0.1$, the temperature here
$(0.9 \mathrm{R})$ decreases in an equal slope with the increase of $F_{0}$ under the four schemes.

(2) Surrounding Rock Zone (Zone II). According to the temperature data at $1 \mathrm{R}$ and $0.9 \mathrm{R}$ on both sides of the TIG layer, the temperature at $1 \mathrm{R}$ drops sharply at the beginning of ventilation when $F_{0}=0.1$, but the range of drop is much smaller than that of the TIG layer wall, leading to the formation of a relatively large temperature difference on the 


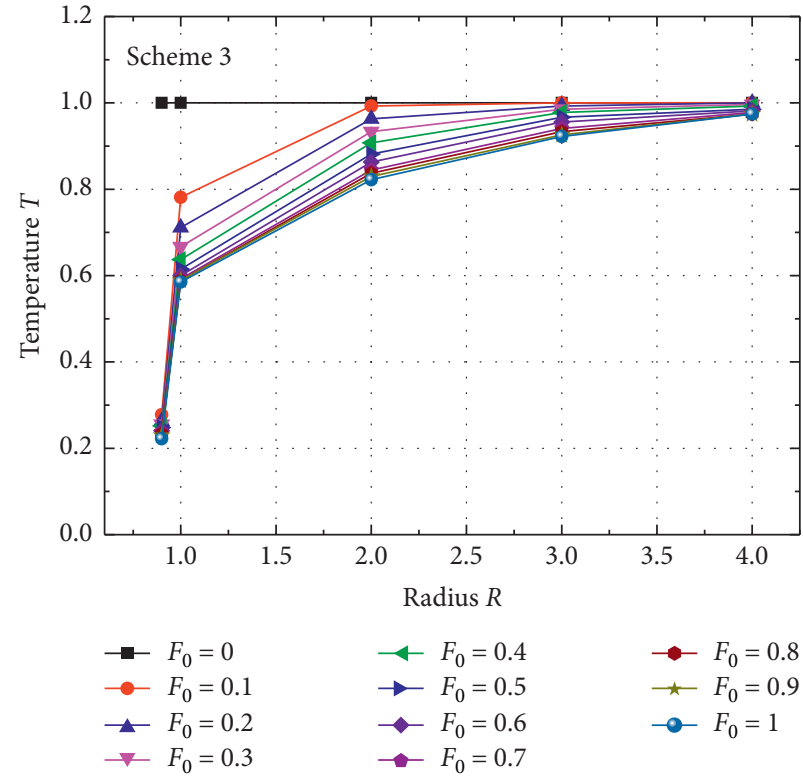

(a)

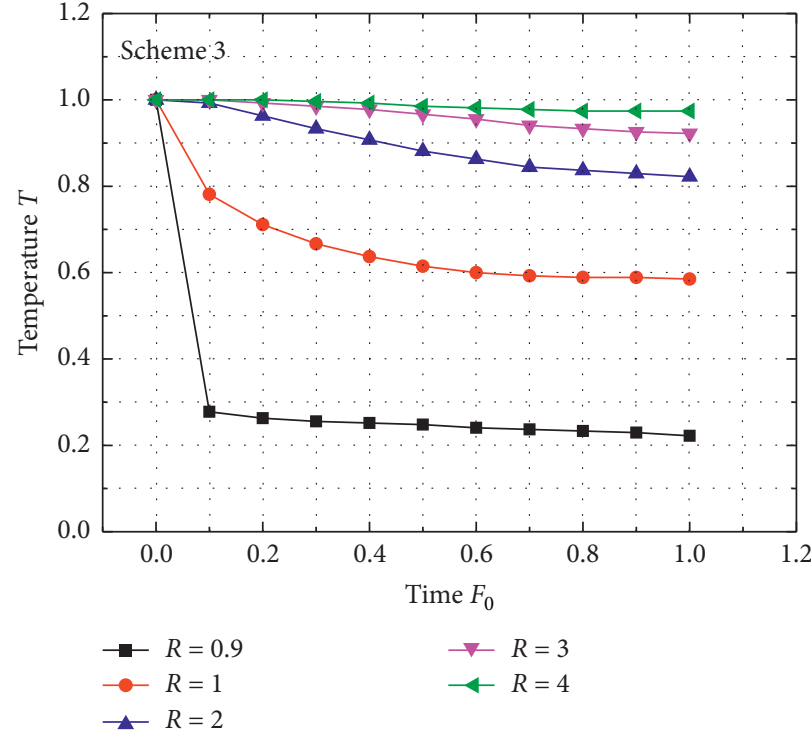

(b)

Figure 8: $T-R$ curve and $T-F_{0}$ curve under the working conditions of Scheme 3. (a) $T-R$ curve. (b) $T-F_{0}$ curve.

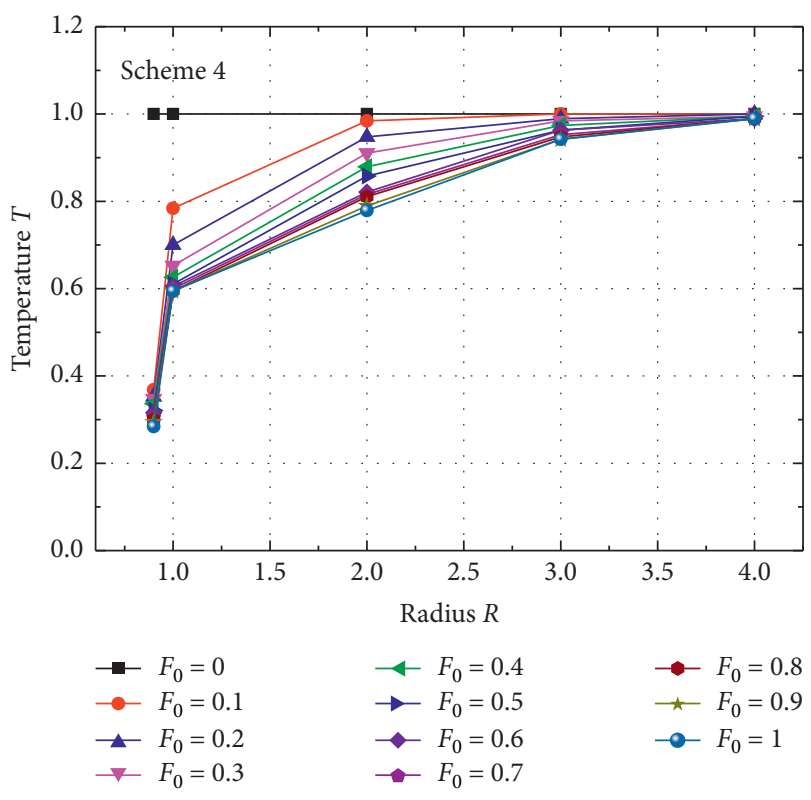

(a)

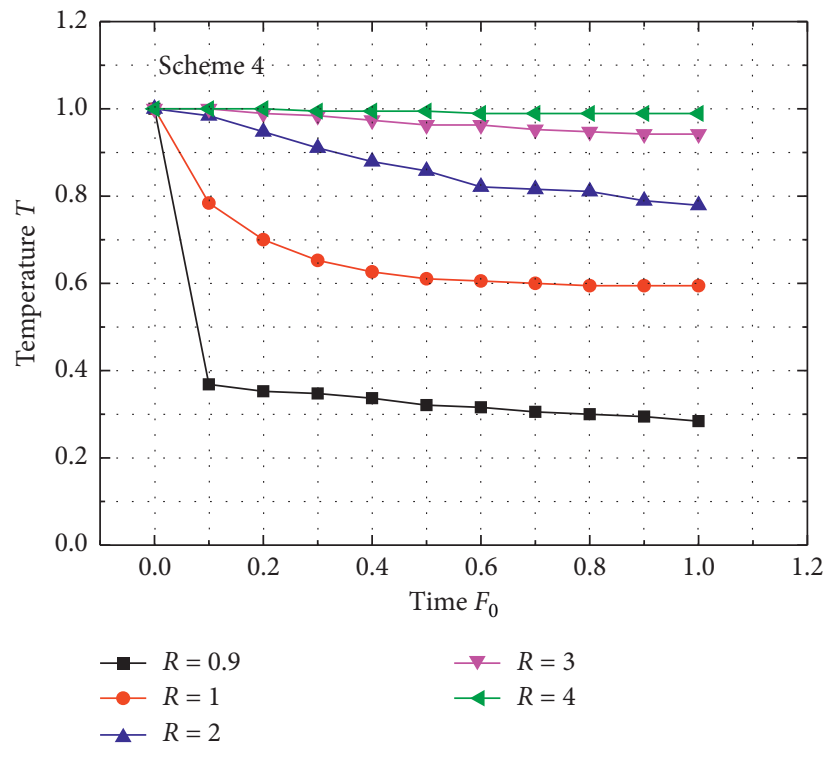

(b)

FIgURE 9: $T-R$ curve and $T-F_{0}$ curve under the working conditions of Scheme 4. (a) $T-R$ curve. (b) $T-F_{0}$ curve.

TABLE 7: Relationship between dimensionless temperature and dimensionless radius.

\begin{tabular}{lcccc}
\hline$F_{0}$ & $P_{1}$ & $P_{2}$ & $P_{3}$ & Correlation coefficient \\
\hline 0.2 & -1.06 & -1.47 & 1.01 & 0.99 \\
0.4 & -0.83 & -0.88 & 1.02 & 0.99 \\
0.6 & -0.82 & -0.67 & 1.04 & 0.99 \\
0.8 & -0.78 & -0.47 & 1.09 & 0.99 \\
1 & -0.79 & -0.36 & 1.15 & 0.99 \\
\hline
\end{tabular}




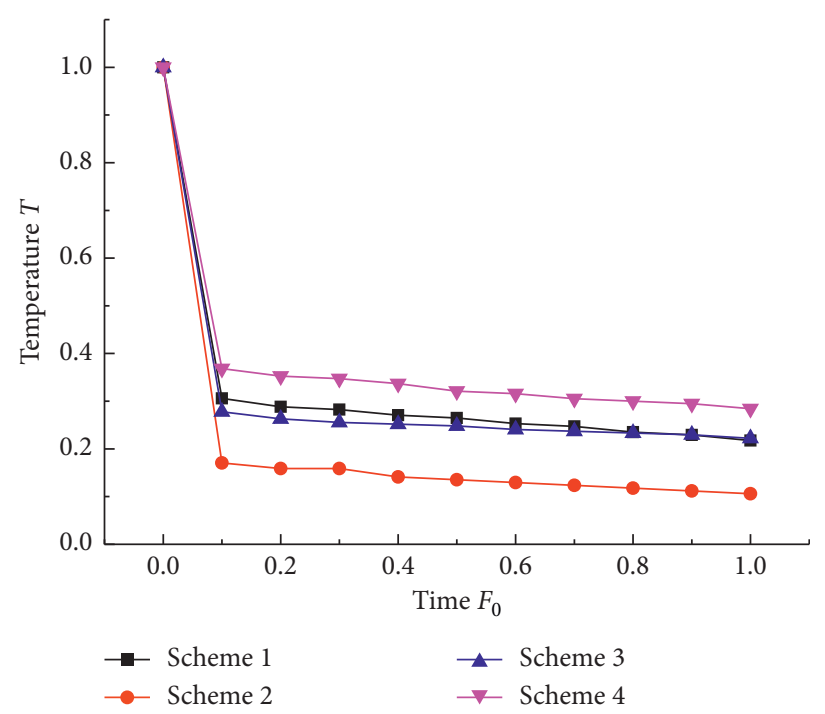

Figure 10: Variations of temperature $\mathrm{T}$ on the TIG layer wall at $0.9 \mathrm{R}$ with time.

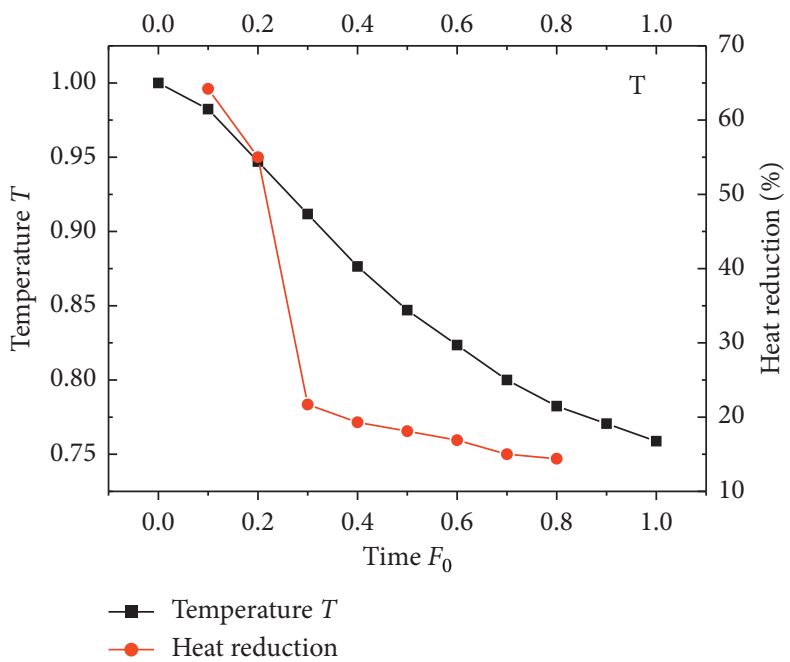

FIGURE 11: Relationship between the temperature drop at $2 \mathrm{R}$ and the heat reduction of the surrounding rock under Scheme 1.

two sides. The temperature at $1 \mathrm{R}$ declines at a gradually decreasing rate with the increase of $F_{0}$ and tends to level off when $F_{0}=0.8$.

The temperatures at $2 \mathrm{R}$ in the surrounding rock decreases with the increase in $F_{0}$, but their temperature variation rates differ from that of the wall. The temperature drop rates keep growing before $F_{0}=0.2 \sim 0.4$, and they tend to level off after $F_{0}>0.4$, as shown in Figure 6(b). Since $3 \mathrm{R}$ and $4 \mathrm{R}$ are closer to the outer boundary, the abovementioned law is not evidently exhibited at the two positions. However, it can be inferred that for the position father away from the wall, the turning point of the temperature drop rate appears later temporally. This indicates that the inside of the surrounding rock exhibits a lagging response time for the adjustment of boundary temperature disturbance, and the longer the distance is, the longer the response time is. Compared with the non-TIG roadway, the TIG roadway presents more obvious lagging response time.
By comparing Figure 6 with Figures 7-9, it is found that the variations of ventilation parameters (wind speed and wind temperature) and virgin rock temperature do not alter the variation trends of the $T-R$ curve and $T-$ $F_{0}$ curve. Besides, variations of these parameters exert no significant effect on the internal temperature field of the TIG roadway in this experimental scope. As presented in Figure 10, the variations of ventilation parameters (wind speed and wind temperature) and virgin rock temperature directly affect the wall temperature, which demonstrates that the TIG layer has a significant effect on the stability of the temperature field of internal surrounding rock.

Figure 11 is a comparison between the temperature drop and the heat reduction at $2 \mathrm{R}$ of the surrounding rock under Scheme 1. From Figure 11, the heat reduction of the TIG roadway is significantly lowered after $F_{0}>0.3 \sim 0.4$, which corresponds to the gentle temperature drop rates at $2 \mathrm{R}, 3 \mathrm{R}$, 
and $4 \mathrm{R}$, as in Figure $6(\mathrm{~b})$. This suggests that the TIG structure should be constructed in the early stage of ventilation in order to achieve an excellent effect.

\section{Conclusions}

In this paper, a kind of mine TIG material that boasts light weight, thermal insulation, and large load-bearing capacity was developed by taking cement, sand, fly ash, and vitrified microsphere as raw materials and density, thermal conductivity, and UCS as evaluation indexes. Furthermore, the thermal insulation effect of the TIG layer was analyzed with the aid of a physical similarity simulation experimental apparatus independently developed by our research team. Besides, the temperature field characteristics of the surrounding rock were researched on. The following main conclusions were drawn:

(1) The thermal insulation effect of the TIG material in the high geo-temperature roadway was analyzed by means of physical similarity simulation. The temperature disturbance time, temperature drop rate, and temperature drop range of radial points in the surrounding rock of the TIG roadway and the nonTIG roadway were compared. The results show that, in the early stage of TIG layer construction, the heat reduction of the roadway wall reaches over $60 \%$, which directly demonstrates the excellent thermal insulation performance of the TIG material. The changes in ventilation parameters (wind speed and wind temperature) and virgin rock temperature do not notably influence the internal temperature field of the surrounding rock of the TIG roadway, which suggests that the TIG layer has an important influence on the stability of the surrounding rock temperature field. This indirectly demonstrates the good thermal insulation performance of the TIG material.

(2) Characteristics of temperature field in the surrounding rock of the TIG roadway were researched on. The thermal flux density $(T / R)$ of surrounding rock near the roadway wall is larger in the early stage of ventilation; then, the thermal flux densities tend to be consistent as the ventilation time $F_{0}$ increases from 0 to 1 . This indicates that the temperature field of surrounding rock regains a balance, which marks the end of temperature disturbance. An obvious exponential function relationship exists between $T$ and $R$ during the entire time period.

(3) Different radial points of the surrounding rock in the TIG roadway exhibit varying characteristics of temperature drop. The temperature outside the TIG layer drops sharply as ventilation begins, and then, the temperature drop develops in an equal slope. The temperature of the inner wall of the TIG layer declines in a smaller range than that of the outer wall at the beginning of ventilation, after which the temperature drop rate decreases gradually. The temperature drop inside the surrounding rock increases first and, then, decreases. The inside of the surrounding rock exhibits a lagging response time for the adjustment of boundary temperature disturbance; and the longer the distance is, the longer the response time is. Compared with the non-TIG roadway, the TIG roadway presents more obvious lagging response time. The stage of decreasing temperature drop rate of the surrounding rock corresponds to the stage of gentle heat reduction of the wall.

\section{Data Availability}

The data used to support the findings of this study are available from the corresponding author upon request.

\section{Conflicts of Interest}

The authors declare no conflicts of interest.

\section{Acknowledgments}

The authors are grateful to Dr. Zhaoyang Ma from Monash University for his support and contribution in the language proofreading. This research was funded by the National Natural Science Foundation of China, grant no. 51674242.

\section{References}

[1] J. Y. Wang, Geothermology and its Application, Science Press, Beijing, China, 2015.

[2] Z. P. Xie, "Distribution law of high temperature mine's thermal environment parameters and study of heat damage's causes," Procedia Engineering, vol. 43, pp. 588-593, 2012.

[3] P. Ma, "Application and research of prevention and control technique of thermal damage in deep mining of coal mine," Value Engineering, vol. 37, no. 3, pp. 125-126, 2018.

[4] K. Carpenter, P. Roghanchi, and C. Kocsis, "Investigating the importance of climatic monitoring and modeling in deep and hot US underground mines," in Proceedings of 15th North American Mine Ventilation Symposium, pp. 1-4, Virginia Tech, Virginia, 2015.

[5] B. Belle and M. Biffi, "Cooling pathways for deep Australian longwall coal mines of the future," International Journal of Mining Science and Technology, vol. 28, no. 6, pp. 865-875, 2018.

[6] N. Slazak, D. Obracaj, and M. Borowski, "Methods for controlling temperature hazard in Polish coal mines," Archives of Mining Sciences, vol. 53, no. 4, pp. 497-510, 2008.

[7] X. J. Yang, Q. Y. Han, J. W. Pang et al., "Progress of heathazard treatment in deep mines," International Journal of Mining Science and Technology, vol. 21, no. 2, pp. 295-299, 2011.

[8] Z. J. Wan, S. K. Bi, Y. Zhang et al., "Framework of the theory and technology for simultaneous extraction of coal and geothermal resources," Journal of China Coal Society, vol. 43, no. 8, pp. 2099-2106, 2018.

[9] Y. Zhang, Transient Temperature Field of Surrounding Rock of the High Geothermal Roadway and its Heat Control Mechanism by Heat Insulation, China University of Mining and Technology, Xuzhou, China, 2013. 
[10] C. Kang, W. Zha, L. Zhang et al., "Control theory and technology analysis of high temperature in deep mining," Safety in Coal Mines, vol. 47, no. 5, pp. 89-93, 2016.

[11] M. He, X. Cao, Q. Xie et al., "Principles and technology for stepwise utilization of resources for mitigating deep mine heat hazards," Mining Science and Technology (China), vol. 20, no. 1, pp. 20-27, 2010.

[12] M. G. Zhang, X. J. Zhang, and Y. Zhang, "Discussion on comprehensive control of mine heat hazard," Advanced Materials Research, vol. 726-731, pp. 854-858, 2013.

[13] Y. Zhang, Z.-J. Wan, B. Gu, C.-B. Zhou, and J.-Y. Cheng, "Unsteady temperature field of surrounding rock mass in high geothermal roadway during mechanical ventilation," Journal of Central South University, vol. 24, no. 2, pp. 374-381, 2017.

[14] H. P. Kang, G. F. Wang, P. F. Jiang et al., "Conception for strata control and intelligent mining technology in deep coal mines with depth more than $1000 \mathrm{~m}$," Journal of China Coal Society, vol. 43, no. 7, pp. 1789-1800, 2018.

[15] K. Trapani, A. Romero, and D. Millar, "Deep mine cooling, a case for Northern Ontario: Part II," International Journal of Mining Science and Technology, vol. 26, no. 6, pp. 1033-1042, 2016.

[16] X.-P. Feng, Z. Jia, H. Liang et al., “A full air cooling and heating system based on mine water source," Applied Thermal Engineering, vol. 145, pp. 610-617, 2018.

[17] M.-C. He, "Application of HEMS cooling technology in deep mine heat hazard control," Mining Science and Technology (China), vol. 19, no. 3, pp. 269-275, 2009.

[18] L. Aditya, T. M. I. Mahlia, B. Rismanchi et al., "A review on insulation materials for energy conservation in buildings," Renewable and Sustainable Energy Reviews, vol. 73, pp. 1352-1365, 2017.

[19] S. Schiavoni, F. D'Alessandro, F. Bianchi, and F. Asdrubali, "Insulation materials for the building sector: a review and comparative analysis," Renewable and Sustainable Energy Reviews, vol. 62, pp. 988-1011, 2016.

[20] T. Chien Yet, R. Hamid, and M. Kasmuri, "Dynamic stressstrain behaviour of steel fiber reinforced high-performance concrete with fly ash," Advances in Civil Engineering, vol. 2012, 2012.

[21] Z. Zhang, Y. Zhu, H. Zhu, Y. Zhang, J. L. Provis, and H. Wang, "Effect of drying procedures on pore structure and phase evolution of alkali-activated cements," Cement and Concrete Composites, vol. 96, pp. 194-203, 2019.

[22] A. Noushini, K. Vessalas, G. Arabian et al., "Drying shrinkage behaviour of fibre reinforced concrete incorporating polyvinyl alcohol fibres and fly ash," Advances in Civil Engineering, vol. 2014, 2014.

[23] G. F. Li, Research on Technology of Active Cooling Supporting Structure in High Temperature Road Way, Taiyuan University of Technology, Taiyuan, China, 2010.

[24] X. L. Zhang, The Development of Mine Thermal Insulation Material and the Expermental Study of it's Performance, Henan Polytechnic University, Henan, China, 2012.

[25] F. Yang, Experimental Study of High Temperature Deep Roadway New Insulation Materials, Anhui University of Science and Technology, Anhui, China, 2016.

[26] J. Wang, C. Zhu, Q. Hou et al., "Experimental study on heat insulation of vermiculite mortar in heat harmful mine," Safety in Coal Mines, vol. 45, no. 9, pp. 13-15, 2014.

[27] L. Liu and J. Zhang, "Thermal insulation composite material for governance of underground thermal hazard and its application," Journal of Shandong University of Science \& Technology, vol. 36, no. 1, pp. 46-53, 2017.
[28] F. F. Wang, D. C. Mei, and J. Y. Pang, "Research on performance of thermal insulation materials in underground high-temperature tunnels," Coal Technology, vol. 36, no. 2, pp. 187-189, 2017.

[29] X. H. Zhou, X. Tang, and D. P. Song, “Thermal insulation performance affected by thermal physical parameters of thermal insulation layer in active thermal insulation tunnel," Mining Safety and Environmental Protection, vol. 46, no. 1, pp. 18-22, 2019.

[30] Y. J. Wang, G. Q. Zhou, Y. Z. Wei et al., "Experimental research on changes in the unsteady temperature field of an airway in deep mining engineering," Journal of China University of Mining \& Technology, vol. 40, no. 3, pp. 345-350, 2011.

[31] Y. Zhang, Z. Wan, B. Gu et al., "An experimental investigation of transient heat transfer in surrounding rock mass of high geothermal roadway," Thermal Science, vol. 20, no. 6, 53 pages, 2016.

[32] S. Zhu, S. Wu, J. Cheng, S. Li, and M. Li, "An underground airroute temperature prediction model for ultra-deep coal mines," Minerals, vol. 5, no. 3, pp. 527-545, 2015.

[33] H. Z. Wang, Study on Characteristics of Heat and Mass Transfer in Working Face of High-Temperature Mine, China University of Mining and Technology, Xuzhou, China, 2016. 